\title{
An Audio-Visual Integrated Approach to Japanese Language and Culture
}

\author{
Xuexin Liu \\ Spelman College \\ 350 Spelman Lane, Atlanta \\ Georgia 30314, USA
}

\begin{abstract}
One of theobvious challenges in teaching a foreign language is how to provide learners with access to the target language environment, where learners can receive, comprehend and interact with the target language input. 'Acculturation' is an important process of second or foreign language acquisitionbecause the target language knowledge and skills are embedded in and driven by the target culture.This paper proposes an audio-visual integrated approach to Japanese language and culture as a bridge to acculturation for desirable learning outcomes. It discusses why it becomes necessary to use audio-visual materials as a teaching strategy, suggests how such materials should be applied to classroom teaching and learning, outlines the roles that teachers should play in an audio-visual classroom, and proposes the methods of using audio-visual materials. It concludes that it is indispensable to use technology and integrate it into the foreign language curriculum to enhance meaningful and successful learning.
\end{abstract}

Keywords: audio-visual, acculturation, foreign language, input, materials, roles, methods

\section{Introduction}

Teaching a foreign language in a non-native language environment, such as teaching Japanese in the United States or other non-Japanese speaking countries, often encounters some particular challenges or difficulties due to no or rather limited access to the natural target language input and cultural experience. Professional teachers of foreign languages need to consider how effective methodologies can be created and developed for engaging students in the learning process, what materials and resources should be adopted for teaching and learning, and how native or native-like input can be provided for interactive learning. To do so, teachers can either develop their own methodologies and materials or selectively adopt some existing models and approaches. This paper introduces an audio-visual integrated approach to teaching Japanese language and culture as one of the effective ways to serve one of the particular dimensions of learning style: the preference that learners show toward either auditory or visual input or both. As often observed, this dimension of learning style is very salient in a formal classroom setting.Auditory learners tend to prefer listening to lectures and audiotapes, and visual learners tend to prefer reading and studying drawings, photos, charts, and other graphic or concrete presentations. Most successful learners tend to utilize both auditory and visual input. Thus, it becomes necessary to consider the questions: Why is audio-visual integrated approach important for teaching Japanese language and culture? What are the motivations for an audio-visual integrated approach to teaching Japanese language and culture? What materials or technological resources should be used for effective teaching and learning? What are the roles of teachers in an audio-visual classroom setting? How can practical techniques be used for using audio-visual materials? By discussing such questions, this paper claims that the integration of auditory and visual input is an important and effective tool for learners to acquire better target language skills and gain intercultural awareness and competence, and teaching any foreign language and culture through technology promotes outcome oriented successful learning.

\section{Audio-visual integration as a bridge to acculturation}

The Acculturation Model (Schumann, 1978a, 1978b, 1878c) is one of the most prominent socio-cultural models established to account for the successful acquisition of a second language by immigrants in majority language settings. Though this model specifically excludes learners who receive formal instruction or learn a foreign language in a nontarget language speaking environment (e.g., learning Japanese in the United States or other non-Japanese speaking countries), the notion of 'acculturation' also applied to the process of foreign language learning. Schumann sees 'acculturation' as governing the extent to which learners achieve target language norms and or competence. "Second language acquisition is just one aspect of acculturation and the degree to which a learner acculturates to the targetlanguage group will control the degree to which he acquires the second language" (Schumann, 1978a, p.34). 
Thus, the significant implication of this model is that acculturation is a process of becoming adapted to the target culture in order for the learner to successfully acquire the target language knowledge and skills as embedded in and driven by the target culture. The essence of the Acculturation Model is its recognition of the developmental nature of second language acquisition (also, foreign language acquisition) and seeks to explain differences in learners' rate of development and also in their ultimate level of achievement in terms of the extent to which they adapt to the target language culture. Schumann suggests that acculturation affects second language acquisition by its effect on the amount of contact learners have with native speakers of the language they are learning. The greater the contact, the more acquisition takes place. Schumann (1986) further suggests that acculturation may also affect the nature of the verbal interaction that learners take part in and thus the quality as well as the quantity of the target language input.

Though it is difficult to measure acculturation and there is no principled way of weighting the variables involved in acculturation, the relevance of this model to foreign language acquisition lies in the relation between language learning and socio-cultural learning. That is, learning a second language or a foreign language without the target language or foreign language socio-culture learning, the degree of success will be rather limited. What makes foreign language acquisition more complicated or difficult lies in the fact that foreign language acquisition takes place in a non-target language speaking environment and learners have no or rather limited access to natural target language input.

This paper proposes an audio-visual integrated approach to Japanese language and culture as a bridge to acculturation in consideration of some predictable 'weaknesses' of foreign language learners: (1) They acquire knowledge and skills of the target language mainly through classroom learning and technologies, such as language labs and foreign language learning websites. (2) They do not have direct contact with native speakers of the target language and thus do not receive or receive rather limited natural target language input. (3) Their knowledge of the target language is typically no identical to that of the native speaker, and few foreign language users can surpass native speakers. Foreign language users' grammar, accent and pragmatic use of the target language give away that they are non-native speakers. That is, their use of the foreign language tends to be unnatural, non-idiomatic or non-native like. Foreign language learners' weaknesses are commonly observed in most learning settings where the target language is taught and learned as a foreign rather than second language (cf. Cook, 2002).

As a bridge to Japanese acculturation, an audio-visual integrated approach can create a 'good' foreign language learning environment where the instructor can introduce Japanesesociety, cultural traditions and customs, social manners of Japanese people, Japanese discourse interactions, and so on by using films, DVDs, pictures, CDs, animate movies/cartoons, etc. in relation to particular parts of Japanese language learning in the classroom setting. Since culture is an integral part of the interaction between language and thought; cultural patterns, customs, andways of life are expressed in language, and culture-specific worldviews are reflected in language, it becomes compulsory for instructors to create such a 'good' language-learning environment to overcome the potential, possibly serious, weaknesses of foreign language learning for better learning outcomes.

\section{Audio-visual integration as a teachingstrategy}

Different from any other type of learning, language learning is a complex process, which requires constant natural language input, intake and output through communicative interaction. What makes this process complex is that it involves language information processing mechanisms and learners' mental activities. What makes foreign language learning more difficult than second language learning lies in the fact that in foreign language learning situations, there is no natural target language environment and lack of natural target language input. Though adult second/foreign language acquisition differs from child first or second language acquisition in several aspects, the availability of sufficient natural language input is never dispensable. In foreign language learning settings, most natural language input is only from the textbooks written in the target language or provided by instructors as native speakers of the language or as non-native speakers of the language with native-like proficiency. In addition to the nature of natural language input, learners need mechanisms to perceive and process incoming language input. Without successfully processed input, intake (i.e., comprehended language information) would be incomplete or impossible, and without intake, speech output would be incomplete or impossible.

Teaching through technology is well understood as the application of scientific knowledge to practical teaching tasks so as to enhance learning for better results. Technologies always emerge from the needs of society, and teachers can take advantage of technologies relevant to the teaching-learning situation. One of the effective ways to make natural language input available to a foreign language teaching-learning situation is to provide audio-visual materials. As Wright (1976) pointed out, many media and many visual presentation styles can be useful to language learners. This means that all audio-visual materials, as long as they are purposefully and appropriately selected for the teachinglearning purpose, should have positive contributions to language learning and invite effective learning results. 
As River (1981) claimed, both audio and visual means not only offer learners natural language input but also contribute to learners' understanding of another culture by providing direct contact with speakers of the target language. Foreign language teachers face a common problem of lack of both direct input and accurate match between foreign words and their lexical concepts. Teachers' objective is to help their studentsto understand and remember foreign words and expressions in order for them to express their thoughts in the foreign language. In this case the use of audio-visual means and techniques can be a great help in stimulating and facilitating the learning of a foreign language. In other words, the audio-visual integrated approach can play the role of a particular accessory designed to provide natural language input containing all linguistic levels such as phonology, morphology, and syntax. This accessory can become an integral part in teaching the culture of the foreign country.

The importance of audio-visual integrated teaching-learning cannot be overestimated. For example, an attractive slide or a picture illustrating a lexical item or a situational conversational exchange can captivate the attention of learners through speech sounds and physical images. A slide will also arouse the curiosity and interest of learners and induce in them the desire to know more about the subject. A beautiful picture flashed on the screen while a new word or expression is introduced will make a strong and lasting impression upon learners' memory through a mental connection between the picture and the word. Thus, the visual material accompanying the foreign text, such as particular vocabulary items, fixed phrases, idiomatic expressions or sentence patterns, can render its greatest service by providing both visual and mental input. In so doing, teachers can bring the real-life experience and atmosphere of the foreign country into the classroom as accurately and as much as possible.

One of the most appreciated audio-visual materials applied to foreign language learning is video. Canning-Wilson's large-scale survey (2000) reveals that students like learning a foreign language through the use of video. Video can be used in various ways in language teaching, such as replaying television programs on a video recorder for viewing in class or private study or recording and playing back to learners their activities and achievements in learning a foreign language. But our main concern here is how to use video as a visual aid presenting the target language naturally to make language learning meaningful and effective. As commonly observed, most students who have taken several foreign language courses in a formal teaching-learning setting remain insufficient in the ability to understand and use the target language in natural communicative settings. The issues here are how the natural foreign language input can be made accessible to learners and how it can be successfully processed to the extent that input becomes intake as the prerequisite for speech output. The use of video as an accessory becomes one of the solutions because of its natural, rich and valuable resource. As Hemei (1997) reported, students like such an accessory because video presentations are natural, interesting, audio-visually stimulating, and mentally challenging to watch. The advantages and benefits of using video are obvious. For example, video presentations show students a wide range of communicative situations where people naturally behave in the culture whose language they are learning. Thus, language use by people in interaction in various real communicative situations provides natural language input, which can be meaningfully comprehended to the extent that input becomes intake. In addition, video presentations make meaning clearer by illustrating relationships in a way that is too difficult or even not possible with words themselves.

As commonly observed, foreign language learners rely heavily on visual clues to support their input comprehension and there is no doubt that slides, pictures, and videos are obviously among the useful media providing the visual clues to help learners comprehend input (i.e., understanding meaning as conveyed phonologically, morphologically, and syntactically) and understand language use in a particular cultural context. Such media can give learners natural and realistic models to imitate in using the target language and can increase learners' awareness of foreign cultures.

Below are some of the many online resources that can be fully used in any audio-visual integrated approach:

https://www.erin.ne.jp/en

This is a Japanese learning website with many attractive features. It helps learners understand Japan and its culture easily. Viewing the videos drives a variety of challenging games and culture quizzes. The drama-like skits show Japanese everyday life and natural conversations. Learners can read each script of the conversation in kanji, hiranaga and English and can check the meanings of words or expressions while viewing listening to the Japanese script. Learners can also study important points of each skit in the 'key phrases' section with animated characters.

http://genki.japantimes.co.jp

http://anime-manga.jp

These Japanese learning websites provide a series of sequentially designed lessons with exercises. They include conversational movies, basic charts and flash cards for hiragana and katakana demonstrations, vocabulary and grammar exercises, Japanese in anime and manga, kanji quizzes, and so on.

Other commonly used websites, CD-COMs and DVDs for learning Japanese language and culture include: 


\section{Situational Japanese}

DVD-ErigagaChōsen-Nihongo dekimasu (Situational Japanese through DVD and Manga), Japan Foundation. Tokyo: The Bujinsha, 2010.

https://www.youtube.com/watch?v=avoqy0H1CRA\&list=PL7d2kjFHoUe-K5oqgN8jcpBJkALmHjCJ7

Kanji-LOOK AND LEARN: 512 Kanji with Illustrations and Mnemonic Hints. Eri Banno, Yoko Ikeda, Chikako Shinagawa, Koori Tajiyama, and Kyoko Tokashiki. Tokyo: The Japan Times, 2009.

https://www.youtube.com/watch?v=nrNBC8voGAg

\section{Japanese Culture}

https://www.youtube.com/watch?v=N9TTWfEjNwI\&t=14s

https://www.youtube.com/watch?v=PcMaZLiqVpI\&t=135s

https://www.youtube.com/watch?v=029kdjdasyM

Internet Exercises-Animation of Japanese Folktale -Japanese classical story DVD links:

\section{Momotaro}

(Japanese)https://www.youtube.com/watch?v=3k75rkB61Bk

PEACH BOY(English) https://www.youtube.com/watch?v=QSRaaVIxR7E\&t=62s

\section{Tana Bata}

(Japanese)https://www.youtube.com/watch?v=EK0Z2mvh-SY

Tanabata Story with English Subtitles https://www.youtube.com/watch?v=F9_9MM85z6I

\section{KaguyaHime}

(Japanese) https://www.youtube.com/watch?v=YoohVpVo7xk

SHINING PRINCESS (English) https://www.youtube.com/watch?v=mdkiBPtlHzY

\section{Audio-visual integration as a necessary approach to Japanese language and culture}

Like any other foreign language teaching, teaching Japanese language and culture in a foreign country encounters many challenges. One of the most obvious challenges is the language environment in which Japanese language and culture are taught and learned, and the other is students' lack of access to natural Japanese language input. As introduced earlier, one of the most feasible and effective solutions is for teachers to provide audio-visual means as teachinglearning accessories to create a natural-like language environment with sufficient authentic language input.

In addition to the language environment and the access to authentic language input, most American students face another serious learning difficulty, that is, the differences between English and Japanese at all linguistic levels, such as phonology, morphology, and syntax, including the writing systems. As commonly known, Japanese is one of the most difficult Asian languages for American students to learn. Furthermore, since language and culture are interwoven, language learning is part of culture learning, and without learning culture, successful language acquisition would be impossible. This presents American students another learning difficulty, that is, the dramatic differences between American culture and Japanese culture.

Teachers must face such difficulties and challenges and adopt various effective teaching methods or approaches for better learning results. An audio-visual integrated approach is one of the most effective ones. A great advantage of this approach is that it creates a natural language environment and provides authentic language input. DVD movies and TV shows, among others, are made for native speakers. As Katchen (2002) specifically mentioned, it is in this sense that such audio-visual materials provide authentic language input. Another advantage is that teachers can easily use and manipulate audio-visual materials during the teaching-learning process. For example, teachers can step in the process whenever necessary by stopping, restarting or rewinding what is being viewed for several times wherever necessary. When teachers want students to pay special attention to a particular point in the discourse interaction as being viewed, they may selectively make the program run in slow motion, at half speed or without sound (Çakir, 2006). During the process, learners can pay close attention to the language being listened to and interpret or discuss what has been said, recall and repeat it, and so on. Learners can also relate visual clues to meaning such as speakers' body language as reflected in their facial expressions, postures, and gestures in a particular conversational exchange. Moreover, while learners watch and listen to real people communicating with each other in natural settings, they also observe interpersonal relationships among discourse participants, their ways of saying things, and their roles in conversation turns. In such a natural language environment, learners can get a general idea of the culture of the target language, that is, how the target language is actually used by its native speakers. 
A highly motivated and thoughtfully adopted audio-visual integrated approach is predicted to offer learners access to target language input to be processed and understood in a natural environment where speakers' interaction can be observed. The remaining questions are what the roles that teachers should play during the teaching-learning process and what techniques can be used for audio-visual materials to promote meaningful and successful learning.

\section{Teacher's roles in applying an audio-visual integrated approach}

Any teacher who adopts the audio-visual integrated approach to teaching a foreign language should play several key roles in making audio-visual materials as an aid for creating a language learning environment for effective learning. Any audio-visual material should never be considered as a medium to replace the teacher, but as a useful teaching aid. The teacher should play the role as effective as any such a medium in teaching, because it is the teacher who intentionally selects particular audio-visual materials for the teaching-learning purpose, and it is the teacher who mediates between the audio-visual medium and students to facilitate learners' comprehension of what they watch and hear by using some practical techniques.

The teacher should play the roles as identified below to make audio-visual materials truly useful in enhancing learning (cf. Brown, 1993; Brown \& Gonzo, 1994; Gonzalez, Yawkey \& Minaya-Rowe, 2006):

An organizer: Knowing exactly what to lead to success by giving learners useful and leading information, clear instructions and necessary explanations of what they are going to watch and what they are supposed to do.

A controller: Directing what learners do during and/or after the learning process enhanced by the audio-visual medium, selecting what learners watch, and determining variable playing speed of an audio-visual program.

A prompter: Encouraging learners to participate when there is an unexpected silence and/or when learners become confused about what they to do next by reminding or rephrasing the instructions.

A participant: Participating in the activities while using audio-visual materials by offering necessary information whenever necessary, leading learners in the directions of learning, helping learners feel comfort, and facilitating learning.

An assessor: Accessing learners' work to see how well they are performing and evaluating learners' outputs.

To play these roles in the audio-visual integrated approach, the teacher should be well prepared to promote active viewing in order to facilitate successful language learning. This requires the teacher to select the most relevant and appropriate audio-visual materials for particular aspects of learning, such as particular target language phonological, morphological or syntactic items, language use in context, or particular cultural issues related to the language being learned. Of course, the teacher must be familiar with the audio-visual materials as selected before using them in class. What becomes important to the teacher who adopts the audio-visual integrated approach is that s/he should develop a plan for each audio-visual unit, prepare clear viewing guides in consideration of learners' target language levels, and provide assessment rubrics.

\section{Methods of using audio-visual materials for effective learning}

There are different ways of using audio-visual materials in the classroom, and the particular and flexible ways depend on teachers' imagination and innovation for successful learning results. As Canning-Wilson (2000) suggested, only with teachers' various mediating and leading roles in the classroom can the audio-visual medium play its functions in promoting successful learning. To get successful learning results using audio-visual materials as an aid, some practical techniques for teachers to use become necessary. Introduced below are a few most popular ones as selectively conducted in the classroom (cf. Çakir, 2006):

Active viewing: This technique encourages students to actively participate in viewing the audio-visual presentation by paying close attention to the main idea or some necessary details. To do so, the teacher should give his/her students some key questions in order for them to get an overview of the audio-visual content. The students may take notes while viewing in order to answer and discuss these questions in class. The teacher should be aware of his/her students' current levels of learning in order to select the relevant audio-visual content and formulate some appropriate questions.

Freeze framing: This technique gives students opportunities to carefully observe characters' or discourse participants' speech behavior, including their body language, gestures, facial expressions, emotions, and interactions. The teacher can freeze the picture at any point when he/she wants his/her students to pay close attention to some particular words and expressions with the speakers' body language, to ask questions about a particular interactive scene, or ask the students to pay attention to some particular points.Predicting through viewing: This technique, as part of active viewing, prompts students to predict what is going to happen next. The teacher can freeze the scene and ask his/her students to predict what will happen in the next interaction or the discourse participants' speech behavior. In so doing, the students will embed themselves as observers and participants in the on-going scene. 
Role playing: This technique gets students involved as active participants during the learning process. The teacher can assign the roles as viewed in the scene to the individual students for them to play after viewing a video presentation. While performing their assigned roles, the students are required to act out as much of the original version as possible by repeating the original characters' words, expressions or even sentence constructions as they can remember. Such a roleplay helps students better understand how language is actually used by native speakers of a foreign culture and also gives them opportunities to practice their own foreign language skills as used in natural communicative settings.

Recalling for reproduction: This technique encourages students to recall what was said and repeat it to the extent they can, to describe what happened orally or to retell what happened in writing. Recalling for reproduction can be challenging, and it should be beneficial to relatively advanced learners. The teacher should provide necessary guidance, assistance and reassurance.

Dubbing activity: This technique requires students to fill in the missing dialogues in a particular scene after viewing a sound-off video episode or conversational exchange. This activity can be carried out by the students with relatively advanced foreign language skills. To dub a scene, students can practice their foreign language skills at acquired at a certain stage of learning in a natural and creative way.

Follow-up activity: This technique gives students opportunities to practice their foreign language skills as speech output for communication. The teacher can design a follow-up activity after a video presentation in various ways, such as requiring students to do some extended oral practice, to discuss a particular scene, to explain the characters' or discourse participants' speech behavior in a particular exchange, to discuss the relationship between language and culture, and so on.

\section{Conclusion}

It should be obvious that the fundamental reason for adopting the audio-visual integrated approach to teaching a foreign language is to expose learners to the target language for lack of natural target language environment resulting in no or partial access to natural target language input. For this reason, it becomes important for teachers to use technology and integrate it into the foreign language curriculum to enhance meaningful and successful learning (Brown, 1993; Özkan, 2002).

Audio-visual materials such as videos, movies, slides/pictures with sounds, among others, give students opportunities to listen and view actual language use by real people in a particular foreign culture. The target language input is being processed during such an audio-visual process, and the successfully processed or fully comprehended input becomes intake before learners can produce output in natural communicative settings. As Canning-Wilson (2000) observed, even at the most basic level of instruction, video can be a useful form of communication in the classroom since people often interact by body language such as gesture, facial expression and eye contact to convey meaning. Audio-visual materials can present various communicative settings because of their dynamic, immediate and accessible combination of sound and vision. In other words, language learning takes place in an interactive context.

In teaching through technology, the audio-visual medium should be used as an accessory or teaching aid rather than a replacement of teachers. Teachers should play various roles in the classroom to encourage, direct, support and lead students during the learning process, and their roles should be dynamic and flexible enough to meet students' real interests and needs.

To make the audio-visual integrated approach effective and successful, teachers must use some practical techniques as appropriate for different levels of learning. As Katchen (2002) emphasized, without carefully designing an audiovisual integrated approach into the foreign language education curriculum, and without using every necessary and appropriate technique for using audio-visual materials in classroom teaching, teachers cannot make this theoretically motivated and technologically founded approach truly beneficial for both teachers and students.

\section{References}

Brown, H. D. (1993).Principles of language learning and teaching. Englewood Cliffs, NJ: Prentice Hall Regents.

Brown, H. D., \& Gonzo, S. (1994).Readings on second language acquisition. Upper Saddle River, NJ: Prentice Hall Regents.

Çakir, I. (2006). The use of video as an audio-visual material in foreign language teaching classroom. TOJET, 5(4), 6772.

Canning-Wilson, C. (2000).Research in visuals. Video Special Interest Group at the International TESOL Arabia 2000 Conference, Arabia. 
Cook, V. (2002). Background to the L2 user. In V. Cook (Ed.),Portraits of the L2 user (pp. 1-28). Clevedon: Multilingual Matters.

Gonzalez, V., Yawkey, T., \& Minaya-Rowe, L. (2006).English-as-a-second-language (ESL) teaching and learning. Boston: Pearson.

Hemei, J. (1997). Teaching with video in an English class. Journal of English Teaching Forum, 35(2), 45-47.

Katchen, J. E. (1996). Using authentic video in English language teaching: Tips for Taiwan's teachers. Proceedings of the 2002 KATE (The Korea Association of Teachers of English) International Conference (pp. 256-259).

Özkan, B. (2002).The use of video cases in teacher education. TOJET, 1(1), 37-40.

River, W. M. (1981).Teaching foreign-language skills. Chicago: The University of Chicago Press.

Schumann, J. (1978a). The acculturation model for second language acquisition. In R. Gingras (Ed.),Second language acquisition and foreign language teaching (pp. 27-50). Arlington, VA: Center for Applied Linguistics.

Schumann, J. (1878b).The pidginization process: A model for second language acquisition. Rowley, MA: Newbury House.

Schumann, J. (1978c). Social and psychological factors in second language acquisition. In J. Richards (Ed.), Understanding second and foreign language learning: Issues and approaches (pp. 163-78). Rowley, MA: Newbury House.

Schumann, J. (1986). Research on the acculturation model for second language acquisition. Journal of Multilingual and Multicultural Development, 7, 379-392.

Wright, A. (1976).Visual materials for the language teacher. Essex, Longman Wilson. 